\title{
Regional and local variations in atmospheric aerosols using ground-based sun photometry during Distributed Regional Aerosol Gridded Observation Networks (DRAGON) in 2012
}

\author{
Itaru Sano $^{1}$, Sonoyo Mukai ${ }^{2}$, Makiko Nakata $^{3}$, and Brent N. Holben ${ }^{4}$ \\ ${ }^{1}$ Faculty of Science and Engineering, Kindai University, Higashi-Osaka, Japan \\ ${ }^{2}$ REESIT, The Kyoto College of Graduate Studies for Informatics, Kyoto, Japan \\ ${ }^{3}$ Faculty of Applied Sociology, Kindai University, Higashi-Osaka, Japan \\ ${ }^{4}$ NASA Goddard Space Flight Center, Greenbelt, MD, USA \\ Correspondence to: Itaru Sano (sano@info.kindai.ac.jp)
}

Received: 6 May 2016 - Published in Atmos. Chem. Phys. Discuss.: 9 June 2016

Revised: 9 October 2016 - Accepted: 29 October 2016 - Published: 28 November 2016

\begin{abstract}
Aerosol mass concentrations are affected by local emissions as well as long-range transboundary (LRT) aerosols. This work investigates regional and local variations of aerosols based on Distributed Regional Aerosol Gridded Observation Networks (DRAGON). We constructed DRAGON-Japan and DRAGON-Osaka in spring of 2012. The former network covers almost all of Japan in order to obtain aerosol information in regional scale over Japanese islands. It was determined from the DRAGON-Japan campaign that the values of aerosol optical thickness (AOT) decrease from west to east during an aerosol episode. In fact, the highest AOT was recorded at Fukue Island at the western end of the network, and the value was much higher than that of urban areas. The latter network (DRAGON-Osaka) was set as a dense instrument network in the megalopolis of Osaka, with a population of 12 million, to better understand local aerosol dynamics in urban areas.

AOT was further measured with a mobile sun photometer attached to a car. This transect information showed that aerosol concentrations rapidly changed in time and space together when most of the Osaka area was covered with moderate LRT aerosols. The combined use of the dense instrument network (DRAGON-Osaka) and high-frequency measurements provides the motion of aerosol advection, which coincides with the wind vector around the layer between 700 and $850 \mathrm{hPa}$ as provided by the reanalysis data of the National Centers for Environmental Prediction (NCEP).
\end{abstract}

\section{Introduction}

Aerosol data are important indications of the atmospheric environment. Aerosol controls the radiation balance by a lightscattering and absorption process of incident solar radiation. Some types of aerosol indirectly contribute to the balance through the transformation of aerosols into cloud condensation nuclei (IPCC, 2013). The aerosols affect daily local air quality, i.e., visibility and concentrations of $\mathrm{PM}_{2.5}$ and $\mathrm{PM}_{10}$. Villeneuve et al. (2015) have investigated the relationship between mortality and long-term exposure to $\mathrm{PM}_{2.5}$. They pointed out that long-term exposure of more than $11 \mu \mathrm{g} \mathrm{m}^{-3}$ of $\mathrm{PM}_{2.5}$ led to a definite increase in cardiovascular disease that increased mortality rates. The study was performed with a regional PM dataset derived from the Sea-viewing Wide Field-of-view Sensor (SeaWiFS), the Moderate Resolution Imaging Spectroradiometer (MODIS), and the Multi-angle Imaging Spectroradiometer (MISR) measurements and/or combination analyses of the Goddard Earth Observing System (GEOS)-Chem chemical transport model (van Donkelaar et al., 2015). Estimations of $\mathrm{PM}_{2.5}$ based on satellite data require accurate derivations of the vertical profile of aerosol optical thickness (AOT) with fine spatial resolution. Nevertheless, current algorithms for space-based aerosol retrieval are not suitable to resolve this issue because they are tuned for analysis on a global scale, and they sometimes result in a large number of uncertainties not only for a very bright target but also for a complex mixture such as an urban area. 
In the early 1990s, the Aerosol Robotic Network (AERONET) (Holben et al., 1998) was established to support the validation of aerosol products by NASA's EOS-MODIS (Terra) and MODIS (Aqua) missions (King et al., 1992). The AERONET program measures AOT from UV to near infrared with high accuracy. The final accuracy of AOT measurements is less than 0.01 at visible and near-infrared wavelengths, which is achieved by the AERONET standard procedure. The procedure includes many stages, e.g., pre- and post-field calibrations, cloud screening, and interference filter management. Although automatic cloud screening is performed with short and long temporal variations in AOT measurements (Smirnov et al., 2000), all measurements are reprocessed with post-field calibration constants and inspected by AERONET team members, forming a Level 2.0 product. It includes the optical and microphysical properties of aerosols (Dubovik and King, 2000). Dubovik et al. (2002) provided a climatology dataset of global aerosol characteristics, and the categorized results of the characteristics are presented by Omar et al. (2005). The compiled results of aerosol information are useful for the preparation of a lookup table on aerosol retrieval procedures from satellite measurements. There are currently around 400 sites collecting aerosol measurements around the world. However, most of the AERONET site is representative of a targeted area. This deployment style would not provide sufficient measurements for future aerosol retrieval algorithms (Kokhanovsky et al., 2015), such as extracting aerosol properties with fine resolution or vertical distribution, and considering a mixture of ground conditions. In order to apply these requirements, the AERONET group has embarked on a special campaign to deploy many AERONET instruments in a specific area, which is called Distributed Regional Aerosol Gridded Observation Networks (DRAGON). The DRAGON style measurements contribute not only to developing and validating satellite aerosol retrieval algorithms but also to validating the aerosol transport simulation, e.g., the GEOS-Chem (Bey et al., 2001; Martin et al., 2003), the Weather Research and Forecasting (WRF)-Chem (Grell et al., 2005), and Spectral Radiation-Transport Model for Aerosol Species (SPRINTARS) (Takemura et al., 2005).

The first DRAGON was created in the Washington, D.C.Baltimore region in 2011 (Holben et al., 2010). In spring of 2012, DRAGON-Japan and DRAGON-Korea were formed. This work describes regional and local variations of aerosols and also the behavior of transboundary aerosols based on two kinds of ground measurements in a large gridded network (DRAGON-Japan) and a small one (DRAGON-Osaka).

\section{DRAGON-Japan}

\subsection{Background of DRAGON-Japan}

Figure 1 shows the daily average values of AOT at a wavelength of $500 \mathrm{~nm}$ and the Ångström exponent (AE) over the AERONET Osaka station from 2001 to 2014. AE is the wavelength tendency of spectral AOT in log scale. Wavelengths of 440 and $870 \mathrm{~nm}$ were adopted for derivation of standard AERONET AE. AE is an index of the size of particles. Small particles - e.g., carbonaceous, sulfuric, and other anthropogenic particles - have high AEs (Eck et al., 1999). The color of dots in the figure represents four-season data classified as gray for winter (DJF; December, January, February), orange for spring (MAM; March, April, May), green for summer (JJA; June, July, August), and blue for autumn (SON; September, October, November). The AOT-AE relationship shows that aerosols over Osaka for all seasons widely scatter the AOT-AE plane. However, the largest variation including high-AOT-low-AE relationship appears in spring (orange dots). Also those spring measurements take the low $\mathrm{AE}$ value rather than the annual average (black filled circle). Sano et al. (2003) presented the AOT-AE relationship found in results of aerosol measurements in the spring of 2001. At that time, high-AOT, low-AE events were frequently measured at several places in Japan due to Asian dust events; long-term measurements imply the causal feature of this relationship is the dust event. The figure also shows the high-AOT, high-AE measurements frequently appear in summer (green dots).

With respect to aerosols in summertime, we assume the following three conditions: a high oxidant $\left(\mathrm{O}_{x}\right)$ level from local and transboundary emissions, high temperature, and strong solar incident light, which may affect the increase in the conversion process of secondary organic aerosols (SOAs) from volatile organic compounds (VOCs) through the photochemical process (Matsumoto, 2014). SOAs are also known as $\mathrm{PM}_{2.5}$ particles (Hara et al., 2011), which have a high AE. In fact, high values of $\mathrm{O}_{x}$ are recorded at many environmental monitoring stations (AEROS, 2016). AEROS presents high concentrations of $\mathrm{O}_{x}$ in April and May that subsequently decrease in June and July. This suggests that other reasons explain the relationship of high-AOT-high-AE in summer in Japan. Kaneyasu et al. (2005) have reported that events of high concentrations of suspended particulate matter (SPM) occurred through the stagnation of air exchange in Tokyo due to topography and the seasonal rain front (called the Baiu front in Japan). Thus, high values of AOT and AE are realized in Japanese summers. It is possible that spring is the best season to investigate long-range transboundary (LRT) aerosols, including anthropogenic particles and Asian dusts. 


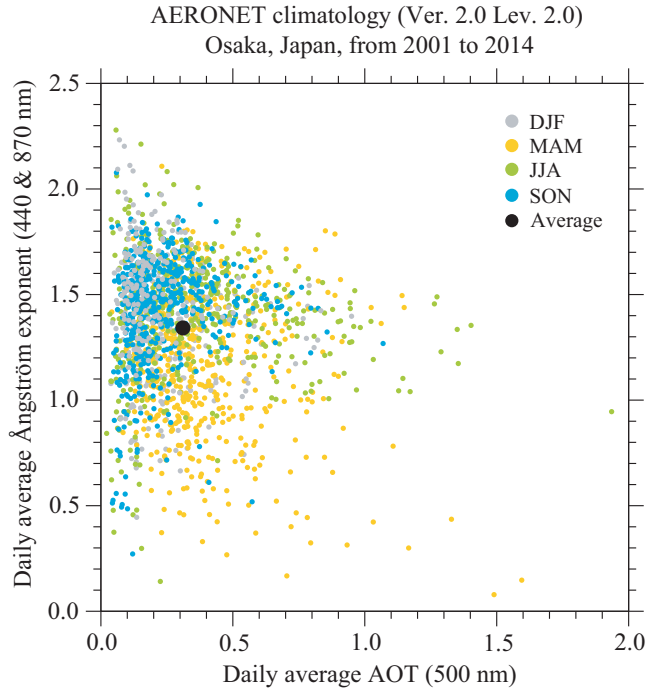

Figure 1. Scattergram of daily average aerosol optical thickness (AOT) at $500 \mathrm{~nm}$ and Ångström exponent (440 and $870 \mathrm{~nm}$ ) over the AERONET Osaka $\left(34.6^{\circ} \mathrm{N}, 135.6^{\circ} \mathrm{E}\right)$ station in Japan from 2001 to 2014 . The colors gray, orange, green, and blue represent the measurements of each season as winter (DJF: December, January, February), spring (MAM: March, April, May), summer (JJA: June, July, August), and autumn (SON: September, October, November), respectively. Black filled circle denotes the annual average. Daily climatology data were processed by the AERONET project (http://aeronet.gsfc.nasa.gov/).

\subsection{Observations during DRAGON-Japan}

Figure 2 represents the instrument setting during DRAGONJapan. As mentioned above, the objective of DRAGONJapan is to investigate LRT aerosols from the Asian continent. Thus, most instruments are set from the western to the middle region of Japan. The National Institute of Environmental Studies (NIES) has been operating the Asian Dust and aerosol lidar observation Network (AD-Net) lidar at Fukue Island, Fukuoka, Matsue, Osaka, and Tsukuba to monitor the dust transportation (Sugimoto et al., 2003; Sano et al., 2008; Shimizu et al., 2015). Thus, the DRAGON-Japan instruments were colocated near the position of AD-Net lidar. In Fig. 2, open circles indicate the positions of both AERONET and lidar instruments during the DRAGON period. The lidar gives attenuated backscatter coefficients of 532 and $1064 \mathrm{~nm}$ as well as a depolarization ratio at the $532 \mathrm{~nm}$ channel. Shimizu et al. (2004) successfully delineated two components of the extinction profile as sphere and non-sphere (dust aerosols) using the lidar measurements. In addition, filled circles in Fig. 2 represent the deployment of an AERONET instrument alone.

Figure 3 shows a time series of hourly average AOT at $500 \mathrm{~nm}$ during DRAGON-Japan. The results from Matsue have been discarded because there were an insufficient number of measurements compared to other locations due to sys-

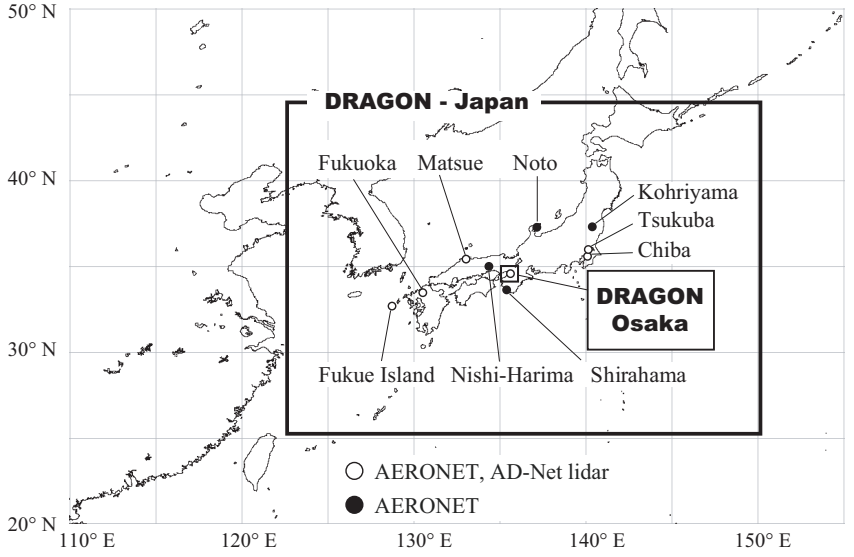

Figure 2. Geographical positions of observational sites for DRAGON-Japan in spring of 2012.

tem problems with the satellite transmitter during the period. In addition, results from Chiba and Kohriyama were also eliminated because average AOT values were similar to Tsukuba. Each average value of AOT and its standard deviation are represented by a red line with a value and gray shading, respectively. The maximum average AOT was recorded at Fukue Island, which is located in the East China Sea (see Fig. 2). Also, the variation of AOT at Fukue is larger than at the other sites. The local emissions would seem to be small on Fukue Island due to a population of only 37000 . Moreover, the measurements were taken at the Fukue aerosol observatory on the peninsula northwest of the island, which is far from the center of town. Therefore, it is natural to consider that the large values of AOT at Fukue represent the dense LRT haze over the entire island. Note that the lowest value denoted by a blue line around $0.1-0.2$ might be the usual local AOT value at all sites. Fukuoka is a millionperson city, which releases a large volume of local emissions. However, two higher values in the middle of April and May imply the results of influence by transported aerosols. This fact is also seen in the sites of Nishi-Harima and Noto, which are located far from large cities in Japan. It might be caused by the influence of LRT aerosols over the Sea of Japan. Even those locations exhibit values of AOT similar to Tsukuba, where the AOT level is most likely affected by emissions from the Tokyo area. It is clear in Fig. 3 that the AOT value at Osaka is rather high compared to the AOT trend with longitude. The Osaka megalopolis emits huge amounts of air pollution, and hence the AOT has a higher value due to the mixture of local emissions with LRT aerosols, which is explored in more depth in the following section. 


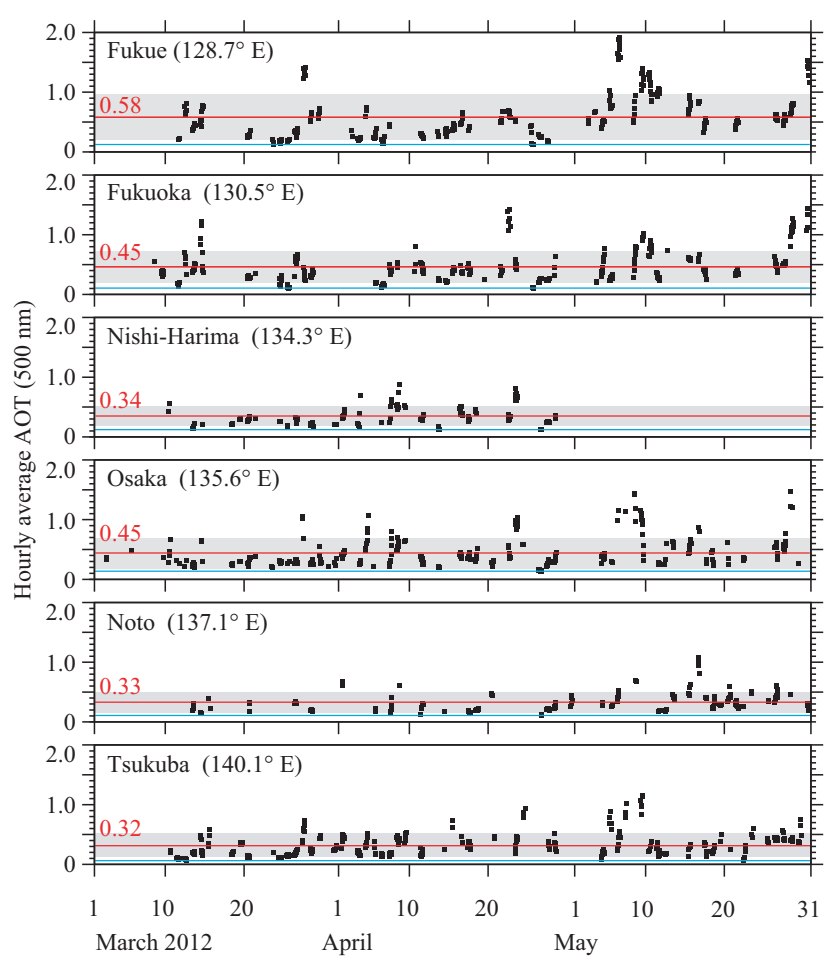

Figure 3. Temporal variation of AOT at a wavelength of $500 \mathrm{~nm}$ during the DRAGON-Japan period. Measurements were taken at Fukue Island, Fukuoka, Nishi-Harima, Osaka, Noto, and Tsukuba (see Fig. 2). The error bars (shaded gray) represent standard deviation at each site. Red lines represent average values at each site.

\section{DRAGON-Osaka}

\subsection{Observations during DRAGON-Osaka}

Figure 4 shows an enlarged area of DRAGON-Osaka, as shown in Fig. 2. A small gridded AERONET sun-sky radiometer network was set from March to May of 2012 in the Osaka metropolitan area. It involved Kobe, Kyoto, Nara, and other cities, and the region is the second-most-populated area in Japan, with a population of 12 million people (see Fig. 4). Aerosol retrieval over this region from a satellite is difficult, although the AERONET sun-sky radiometer has been set since autumn 2001. In fact, MODIS Level 2 aerosol products (MxD04s) sometimes do not provide us with aerosol information from this area. This might be due to such issues as too bright a target, a complex mixture of ground conditions, validation data from only a specific place (AERONET Osaka site), and so on. The first issue occurs by miss-reorganization as a cloudy area. The second issue is a more difficult problem. Land use in a Japanese urban area is very complicated. Because most of Japan (80\%) is mountainous, a majority of the population lives in flat areas. Thus, a pixel of a satellite image may include many types of structures and various ground conditions.

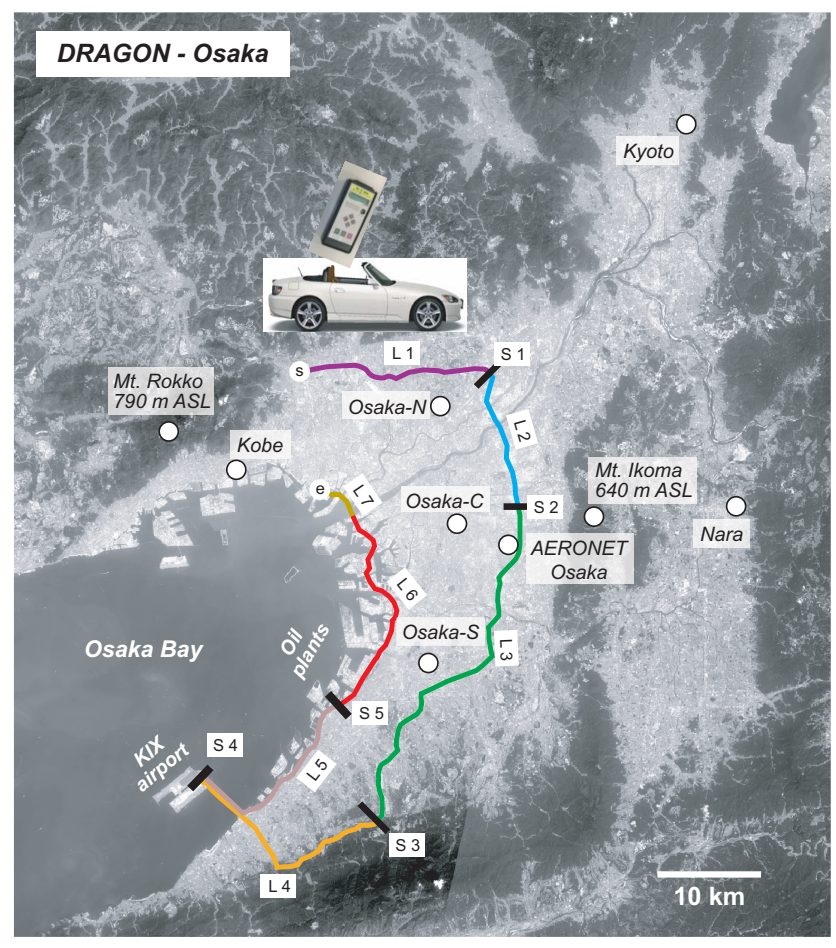

Figure 4. Site deployment during DRAGON-Osaka in spring 2012. Colored lines indicate the path of transect measurements.

DRAGON-Osaka intends to provide local aerosol conditions for an algorithm development of satellite data and an aerosol transport model (Sano et al., 2012). A better understanding of local variations in aerosol properties is important for precise ground modeling. Therefore, the DRAGON-Osaka project constructed a more dense sun-sky radiometer network compared to other DRAGON projects. The AERONET Osaka site in Fig. 4 is a steady site. Other sites (open circles) are temporary sites during the DRAGON-Osaka campaign. Seven AERONET instruments were deployed in flat locations in the Osaka region ([AERONET] Osaka, Kobe, Osaka-N[orth], Osaka-C[enter], Osaka-S[outh], Kyoto, and Nara; characters in square brackets will be omitted hereinafter). Two mountain sites were set in Mt. Rokko and Mt. Ikoma, at around 790 and $640 \mathrm{~m}$ above sea level (a.s.l.), respectively. The Kobe (Kobe Univ.) site faces Osaka Bay, Osaka-N (Kansai Univ.) is surrounded by a residential area, and Osaka-C (Kimoto Electric Co.) is nearest to downtown Osaka. The Osaka (Kindai Univ.) site is located in eastern Osaka close to Mt. Ikoma. Mt. Ikoma is the boundary between Osaka and Nara prefectures. The Osaka$\mathrm{S}$ (Osaka Pref. Univ.) site is in the urban area and is close to large industrial oil plants. The Kyoto site (Kyoto Univ.) is located near the mountain yet is close to a busy section of Kyoto. The Nara site (Nara Women Univ.) is in the center of Nara.

In order to investigate the AOT measurements during DRAGON-Osaka, the measurements are carefully selected 
from the AERONET Version 2 Level 2.0 dataset with checks to detect cirrus cloud contamination by all-sky images, which were taken every $2 \mathrm{~min}$ at the Osaka site. Some measurements are also recovered by checking the images from Level 1 data. It should be noted that the results from Nara are not included because the number of simultaneous measurements was too small to compare with those of other sites. Figure 5 represents three kinds of daily average AOT $(500 \mathrm{~nm})$ during DRAGON-Osaka at each site. The open squares denote the values under every condition, and gray and light blue filled circles present high- and low-aerosol-loading cases, respectively, where the threshold value of AOT for separation is 0.3 . The threshold value was selected with reference to the annual average of AOT $(\sim 0.31)$ at a wavelength of $500 \mathrm{~nm}$ at the AERONET Osaka site from 2001 to 2014 in Fig. 1.

In Fig. 5, the high-AOT group during DRAGON-Osaka is composed of measurements taken on 17, 18, and 24 April and 5 May, and low AOT is observed in the results of 14, 27, and 29 March and 27, 28, and 29 April. The measurements from 8, 9, 12, and 23 April were treated with care because AOT values on those days changed rapidly over time owing to the arrival of LRT aerosols over the target area. These measurements were excluded from the two groups but were included in average AOT results expressed by open squares.

Local variation of AOT over the Osaka area is shown in Fig. 5. Simultaneous measurements from DRAGON-Osaka deployment give a value of 0.03 at most for the differences over all average cases and 0.04 for the high-AOT group. This result implies that local variation of AOT in the Osaka area is not large (less than $\sim 0.04$ ), even when including the LRT aerosols. Note that the results of local variation of AOT are derived from the measurements at lowland sites, i.e., Kobe, Osaka-North, Osaka-Center, Osaka, Osaka-South, and Kyoto.

DRAGON-Osaka covers a small area but includes a variety of observational sites from sea level to mountains (Fig. 4). The effect of altitude on local variation of AOT or AOT itself is taken into account by using two couples: Kobe-Mt. Rokko (790 $\mathrm{m}$ a.s.1.) and Osaka-Mt. Ikoma (640 m a.s.1.). It is to be expected that AOT at higher altitudes would have a lower value than that at corresponding lowland sites, though the difference may not be great (see Fig. 5).

Introducing $\triangle \mathrm{AOT}$ as sub-layer AOT values between sea level and mountains gives $\triangle \mathrm{AOT}$ (Kobe) $=\mathrm{AOT}$ (Kobe) - AOT (Mt. Rokko) and $\triangle$ AOT (Osaka) = AOT (Osaka) - AOT (Mt. Ikoma). $\triangle$ AOT(Osaka) is slightly larger than $\triangle \mathrm{AOT}($ Kobe) under clear conditions $(\mathrm{AOT}<0.3)$. This also reflects the local variation previously discussed.

\subsection{Transect measurements}

The transect measurements of AOT were taken on 5 May 2012, during a short Japanese vacation season and, thus, a period of low industrial activity. Accordingly, our experimental results are expected to show LRT aerosols rather than

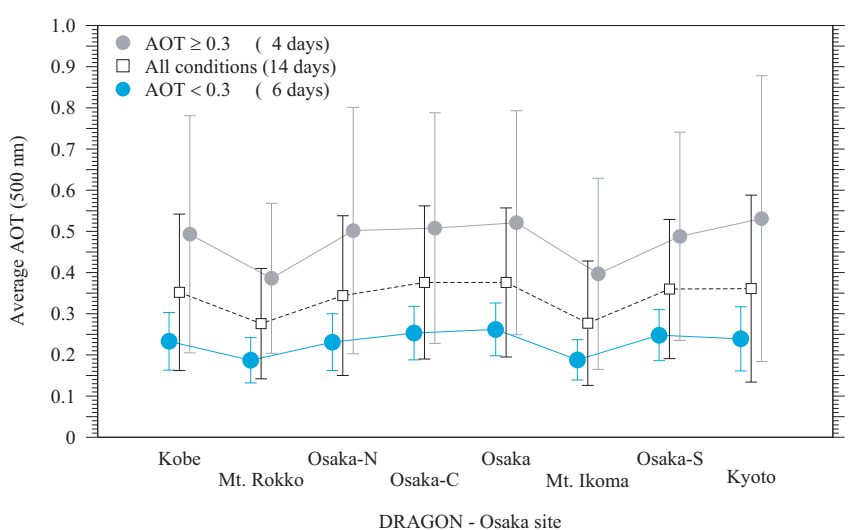

Figure 5. Daily average values of AOT $(500 \mathrm{~nm})$ at each site, classified into three cases, namely turbid days (AOT $\geq 0.3$ ) denoted by solid gray circles, moderate days $(\mathrm{AOT}<0.3)$ by light blue circles, and the values obtained during the DRAGON period by white squares. The error bars represent the standard deviation.

local emissions. The authors attempted to measure the spatial variation of AOT measurements using a combination of a mobile sun photometer (Solarlight Microtops-II (MT-2)) and a Honda S2000 convertible car. The observed wavelengths of AOT measurements by MT- 2 were the same as the AERONET instrument at 380, 440, 500, 670, and $870 \mathrm{~nm}$. Note that the calibration of MT-2 was performed in February 2012 at NASA's Goddard Space Flight Center (GSFC) according to the Maritime Aerosol Network (MAN) procedure (Smirnov et al., 2009). A difficulty of on-board measurements is targeting direct sunlight due to the movement of the car. In order to avoid contaminating noise, two rules were employed: standard deviation of signals, which is automatically recorded by MT-2, should take a small value, and the variation of AE over a few minutes should also be small.

The AOT transect was obtained along the highway, as shown by several colors in Fig. 4, which is divided into seven different colored legs along the roads and five stops labeled L1 to L7 and S1 to S5, respectively. The measurements of the stopping points (S1-S5) were taken at each location where the car was parked, and where a highly accurate AOT was obtained because of the car being still. The car was maintained at a speed of around $70-90 \mathrm{~km} \mathrm{~h}^{-1}$ in order to obtain accurate AOT measurements. The obtained AOT $(500 \mathrm{~nm})$ values are presented in Fig. 6. The measurements in each leg are shown by the same color circles as used in Fig. 4, and black filled circles indicate the measurements at stopping points $\mathrm{S} 1-\mathrm{S} 5$.

The car began at 09:20 LT (local time) from starting point L1 (northwest in the Osaka area) and then traveled east and passed close to the Osaka-N site. The magnitude of AOT (500 nm) gradually increased from $\sim 0.37$ to $\sim 0.43$ during the first $20 \mathrm{~min}$. Then the car changed direction and traveled south (L2). At L2 the AOT gradually decreased from $\sim 0.43$ to $\sim 0.38$. The car passed through the nearest location of the Osaka site in L3. A comparison of AOT by MT-2 with 


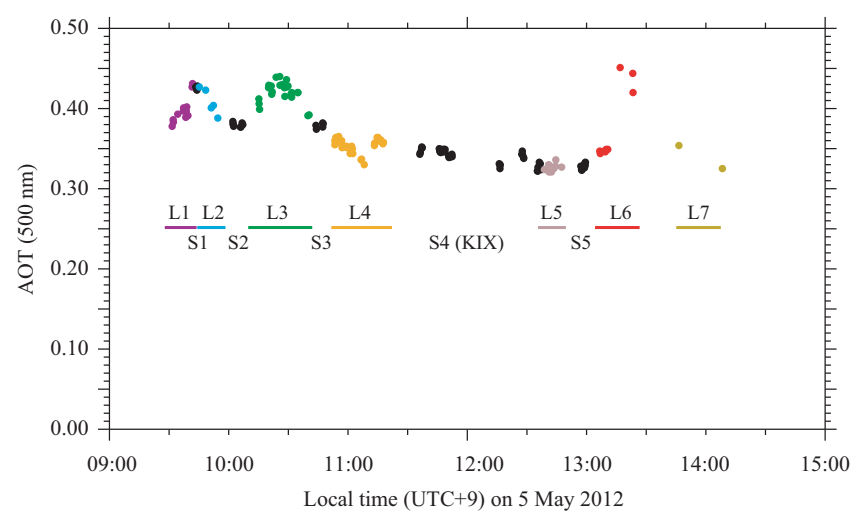

Figure 6. The values of AOT $(500 \mathrm{~nm})$ measured with MicrotopsII by car on 5 May. Each color of the filled circles represents the corresponding color of the transect path in Fig. 4. The black filled circles indicate the measurements of AOT at the stopping points, S1 to S5.

DRAGON-Osaka was performed when the distance between the car and the site was within $1.5 \mathrm{~km}$. The AOT values from MT-2 were 0.406 at 10:15:21 LT and 0.399 at 10:15:31 LT. The value of the Osaka site measurement taken nearest to the time of the car measurements was 0.400 at 10:18:57 LT. The transect measurements during L3 coincided with the products observed at the corresponding Osaka site. This demonstrates that our MT-2 measurements can be utilized to understand the aerosol condition of the Osaka urban area.

AOT gradually decreased along L4 and finally increased near the car stopping point (S4) at Kansai International Airport (KIX). We recorded AOT values for $1 \mathrm{~h}$ with no car movement at KIX. The time series trend is nearly stable, but we see gentle decreases during the period. On-board AOT values were low and stable in L5, the same as at KIX. After the final stop of S5, MT-2's internal memory was full, so the number of measurements was limited in L6 and L7. However, we successfully measured an increase in AOT values from $\sim 0.35$ to $\sim 0.46$ in L6 and a decrease to $\sim 0.33$ in L7. This might be due to dense aerosol that covers only a small region just over the highway.

At the same time the transect measurements are taken, the minute placement of AERONET instruments also must present detailed aerosol information. Figure 7 shows AOT measurements that were observed by the DRAGON-Osaka network. The measurements of Osaka-C, Osaka, and Osaka$\mathrm{S}$ are plotted as thin-dotted, thin-solid, and thin-dashed lines, respectively. Filled squares and open squares represent the values of AOT that were taken at Kobe and Osaka-N sites. Blue cross and red plus symbols show the results of two mountain sites at Mt. Rokko (790 ma.s.1.) and Mt. Ikoma (640 m a.s.1.). Continuous measurements of Osaka-C, Osaka, and Osaka-S were measured by the AERONET sun photometer in high-frequency measurement mode, or the O'Neill mode (or turbo mode in the new TS control box). Measure-

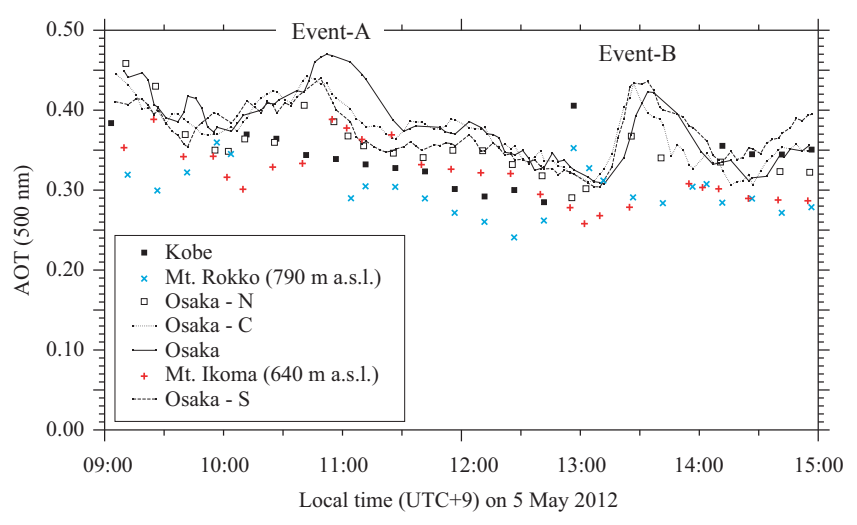

Figure 7. AOT $(500 \mathrm{~nm})$ measurements observed by DRAGONOsaka sites on 5 May 2012.

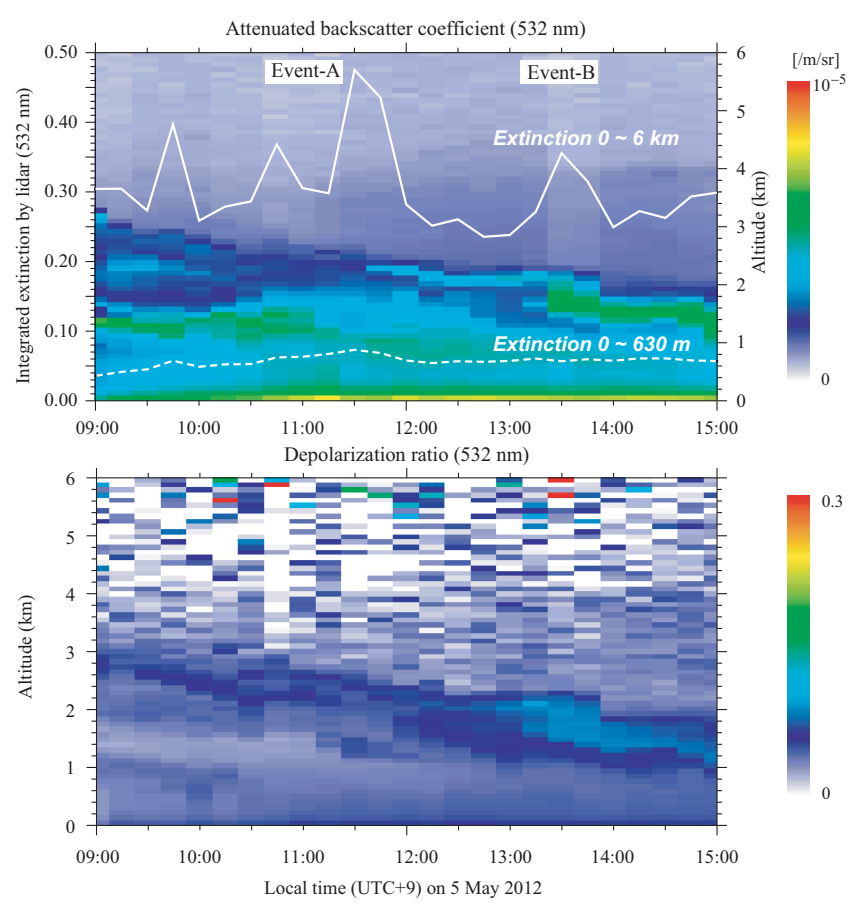

Figure 8. Estimated aerosol optical thickness and attenuated backscatter coefficient (top panel) and depolarization ratio (bottom panel) at $532 \mathrm{~nm}$ by AD-Net lidar at the AERONET Osaka site on 5 May 2012. Solid and dashed lines in the upper panel represent the AOT from the lidar site up to $6 \mathrm{~km}$ and that from the site to up to $630 \mathrm{~m}$.

ments were taken in approximately $3 \mathrm{~min}$ intervals. However, Kobe, Osaka-N, Mt. Rokko, and Mt. Ikoma sites did not employ this continuous measurement scheme because of a different data acquisition system. As seen when comparing Fig. 7 with Fig. 6 with respect to the Osaka site, AOT variations from both the AERONET site and MT-2 coincided, especially AOT peaks around 10:30-11:30 and 13:0014:00 LT. This will be discussed further in Sect. 4. In addition, the first AOT peak from L1 (purple) to L2 (blue) peri- 
(a) NCEP wind @ $850 \mathrm{hPa}$ at 15:00 (UTC+9) on 5 May 2012

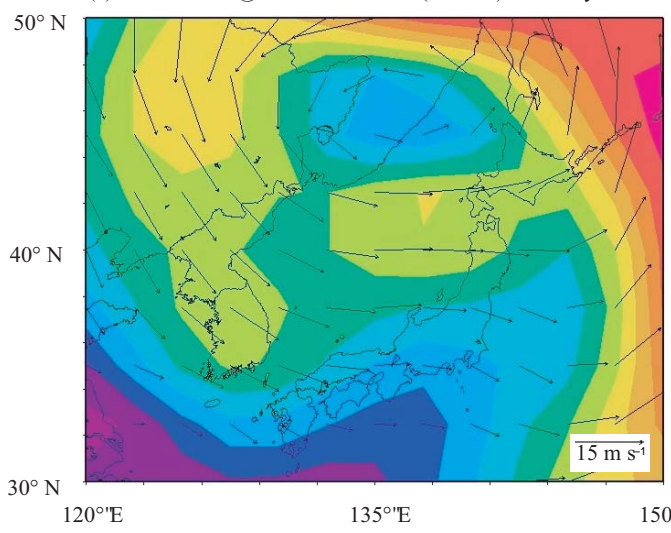

(b) NCEP wind @ $700 \mathrm{hPa}$ at 15:00 (UTC+9) on 5 May 2012

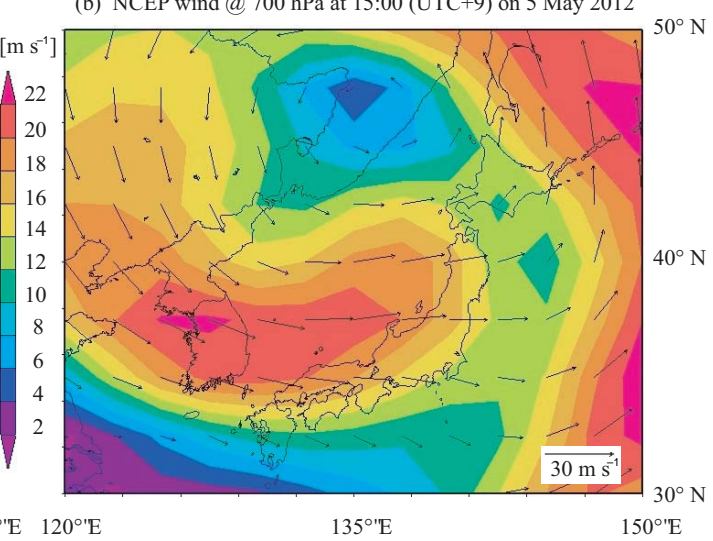

Figure 9. (a) Wind direction and speed at the $850 \mathrm{hPa}$ level over Japan at 15:00 LT (UTC + 9) on 5 May 2012, by NCEP; (b) wind direction and speed at the $700 \mathrm{hPa}$ level over Japan at 15:00 LT (UTC + 9) on 5 May 2012, by NCEP.

ods might be the aerosol plume that passed around 09:20 LT at the Osaka-N site.

AOT measurements at the two mountain sites also detected high AOT values, and differences in AOT between mountain sites and low-altitude sites (Mt. Rokko and Kobe; Mt. Ikoma and Osaka) were not large (less than $\sim 0.08$ ).

\section{Discussion and conclusions}

Two large AOT peaks, as seen in Fig. 7, were observed from 10:30 to 11:30 LT (called event A hereinafter) and around 13:00-14:00 LT (event B), respectively. Both events A and B during DRAGON-Osaka are good representatives of air mass advection because the values of AOT were higher at all sites than the annual average AOT at the AERONET Osaka site (see Fig. 1). Further, during events A and B, AOT showed similar time variations at every location involved in the DRAGON-Osaka project.

Event A started a few minutes after 10:00 LT at all sites and continued until 11:00 LT (see Fig. 7). It is noted that the Osaka site has shown different behaviors from other sites; for example, there were explicitly higher values and longer periods of high values than those at Osaka-C and Osaka-S sites. To understand this difference in behavior, the colocated AD-Net lidar system at the Osaka site is available. The lidar system provided us with the vertical distribution of aerosols. Top and bottom panels of Fig. 8 show the time series of the attenuated backscatter ratio and depolarization ratio, respectively, at a wavelength of $532 \mathrm{~nm}$. The solid and dashed lines on the top panel in Fig. 8 represent the temporal variation of two kinds of AOT $(532 \mathrm{~nm})$ derived from the lidar extinction product (http://www-lidar.nies.go.jp/Osaka/). Each line represents an AOT from the lidar instrument position at $6 \mathrm{~km}$ and $630 \mathrm{~m}$. These results show that aerosol concentration below $630 \mathrm{~m}$ is almost constant when compared to results from $6 \mathrm{~km}$. The peaks of event A and event B correspond to sun photometer results. Clearly, some differences exist between Figs. 7 and 8. However, we assume that the difference between AOT detected by the AERONET Osaka instrument and that by lidar is mainly caused by the direction of observation; i.e., the sun zenith angle of the sun photometer during the time period around 11:00 LT was $\sim 21^{\circ}$, but lidar measures zenith direction alone. It is possible to deduce from Fig. 8 that LRT aerosols over Osaka are concentrated in the upper layer, higher than $600 \mathrm{~m}$ altitude.

With respect to event $\mathrm{B}$, a similar trend of rapid increasing and decreasing of AOT at all sites was found. It is noted that the up and down timing of AOT was synchronized at OsakaC, Osaka-S, and the Osaka site, but event B was slightly delayed at the Osaka site. Shinozuka and Redemann (2011) have pointed out that LRT aerosols retain their concentrations more than local emissions even after long-range transport based on autocorrelated analysis. It is possible to say that these measurements indicate the movement of an air parcel involving a dense concentration of aerosols. This fact coincided with measurements of the depolarization ratio in the bottom panel of Fig. 8, which suggests the existence of LRT dust concentration at that time.

It is of interest that the behavior of AOT at the Osaka site differs slightly from that at the Osaka-C and Osaka-S sites during both events A and B. From the geographic map in Fig. 4, it is seen that the Osaka site is located in the eastward direction from the Osaka-C and Osaka-S sites. The straight distance between Osaka-C and the Osaka site is $5.8(\sim 6) \mathrm{km}$. An AOT value of 0.3450 was recorded at $13: 15: 56 \mathrm{LT}$ at the Osaka-C site. Six minutes later, the Osaka site provided 0.3464 of AOT at 13:21:56 LT. Therefore, it took $6 \mathrm{~min}$ to travel from west to east at a rate of $16 \mathrm{~m} \mathrm{~s}^{-1}$. This assumption coincides with the reanalysis data by NCEP (Kalnay et al., 1996). Figure 9 shows the wind vector information over Japan at the $700 \mathrm{hPa}$ level at 15:00 LT (06:00 UTC) on 5 May 2012, by NCEP. The wind direction and speed were eastward and around $16-18 \mathrm{~m} \mathrm{~s}^{-1}$ over the area. 
The variation in atmospheric aerosols on a regional and areal scale based on DRAGON-Japan and DRAGON-Osaka experiments has been investigated in this work, and the following conclusions have been drawn:

1. Long-range transported aerosols from the continent affect atmospheric conditions in locations far from their origin. In fact, maximum AOT during the DRAGONJapan field campaign was measured at Fukue Island in a remote area of Japan in the East China Sea.

2. The AOT values along the Sea of Japan were high and equaled the values in the suburbs of Tokyo. It might be expected that aerosol was transported over the Sea of Japan.

3. A dense instrument network reveals the magnitude and variation of local aerosols in Osaka, which suggests that variation of AOT at a wavelength of $500 \mathrm{~nm}$ was $\sim 0.04$ during the observation period. This is confirmed by the altitude dependency of AOT.

4. Both transect and DRAGON-Osaka measurements indicate that the distribution of aerosol concentrations is not homogeneous even after transportation over a few thousand kilometers. This suggests that ground remote sensing measurements should be taken more frequently (like the turbo or O'Neill mode in AERONET) and that satellite measurements should be provided at a finer resolution for comparison with the ground-based measurements.

5. The DRAGON style gridded deployment and highfrequency measurements provide information not only on local aerosols but also on long transportation. For example, it was found from DRAGON-Osaka that the transportation speed of the upper aerosol layer coincides with NCEP wind speed.

\section{Data availability}

All datasets are available from the corresponding author upon request.

Acknowledgements. First, the authors are grateful to all collaborators in DRAGON-Japan and acknowledge NASA for the AERONET team and NIES lidar group for data processing. The authors thank the two anonymous reviewers for their valuable comments and suggestions on how to improve the manuscript. This work was supported in part by the Global Change Observation Mission - Climate 1st (GCOM-C1) project by JAXA (no. JXPSPC-308878). This study was supported in part by the Global Environment Research Fund of the Ministry of Environment, Japan (S-12) and JSPS KAKENHI grant numbers 25340019 and $15 \mathrm{~K} 00528$.
Edited by: M. Schulz

Reviewed by: two anonymous referees

\section{References}

AEROS: Atmospheric Environmental Regional Observation System, available at: http://soramame.taiki.go.jp/, last access: 10 March 2016.

Bey, I., Jacob, D. J., Yantosca, R. M., Logan, J. A., Field, B. D., Fiore, A. M., Li, Q., Liu, H. Y., Mickley, L. J., and Schultz, M. G.: Global modeling of tropospheric chemistry with assimilated meteorology: Model description and evaluation, J. Geophys. Res., 106, 23073-23095, doi:10.1029/2001JD000807, 2001.

Dubovik, O. and King, M. D.: A flexible inversion algorithm for retrieval of aerosol optical properties from sun and sky radiance measurements, J. Geophys. Res., 105, 20673-20696, doi:10.1029/2000JD900282, 2000.

Dubovik, O., Holben, B. N., Eck, T. F., Smirnov, A., Kaufman, Y. J., King, M. D., Tanré, D., and Slutsker, I.: Variability of absorption and optical properties of key aerosol types observed in worldwide locations, J. Atmos. Sci., 59, 590-608, doi:10.1175/15200469(2002)059<0590:VOAAOP>2.0.CO;2, 2002.

Eck, T. F., Holben, B. N., Reid, J. S., Dubovik, O., Smirnov, A., O'Neill, N. T., Slutsker, I., and Kinne, S.: Wavelength dependence of the optical depth of biomass burning, urban, and desert dust aerosols, J. Geophys. Res., 104, 31333-31349, doi:10.1029/1999JD900923, 1999.

Grell, G. A., Peckham, S. E., Schmitz, R., McKeen, S. A., Frost, G., Skamarock, W. C., and Eder, B.: Fully coupled "online" chemistry within the WRF model, Atmos. Environ., 39, 6957-6975, doi:10.1016/j.atmosenv.2005.04.027, 2005.

Hara, Y., Uno, I., Shimizu, A., Sugimoto, N., Matsui, I., Yumimoto, K., Kurokawa, J., Ohara, T., and Liu, Z.: Seasonal characteristics of spherical aerosol distribution in eastern Asia: Integrated analysis using ground/space-based lidars and a chemical transport model, SOLA, 7, 121-124, doi:10.2151/sola.2011-031, 2011.

Holben, B. N., Eck, T. F., Slutsker, I., Tanré, D., Buis, J. P., Setzer, A., Vermote, E., Reagan, J. A., Kaufman, Y. J., Nakajima, T., Lavenu, F., Jankowiak, I., and Smirnov, A.: AERONET - A federated instrument network and data archive for aerosol characterization, Remote Sens. Environ., 66, 1-16, doi:10.1016/S00344257(98)00031-5, 1998.

Holben, B. N., Eck, T., Schafer, J., Giles, D., and Sorokin M.: Distributed Regional Aerosol Gridded Observation Networks (DRAGON) White Paper, available at: http://aeronet.gsfc.nasa.gov/new_web/Documents/DRAGON_ White_Paper_A_system_of_experiment.pdf (last access: 10 March 2016), 2010.

IPCC: Climate Change 2013: The Physical Science Basis. Contribution of Working Group I to the Fifth Assessment Report of the Intergovernmental Panel on Climate Change, edited by: Stocker, T. F., Qin, D., Plattner, G.-K., Tignor, M., Allen, S. K., Boschung, J., Nauels, A., Xia, Y., Bex, V., and Midgley, P. M., Cambridge University Press, Cambridge, UK, and New York, USA, 2013.

Kalnay, E., Kanamitsu, M., Kistler, R., Collins, W., Deaven, D., Gandin, L., Iredell, M., Saha, S., White, G., Woollen, J., Zhu, Y., Leetmaa, A., Reynolds, R., Chelliah, M., Ebisuzaki, W., Higgins, W., Janowiak, J., Mo, K. C., Ropelewski, C., Wang, J., 
Jenne, R., and Joseph, D.: The NCEP/NCAR 40-year reanalysis project, B. Am. Meteorol. Soc., 77, 437-470, doi:10.1175/15200477(1996)077<0437:TNYRP>2.0.CO;2, 1996.

Kaneyasu, N., Suzuki, M., Sugimoto, N., Matsui, I., and Shimizu, A.: Meteorological structures during the extensive aerosol pollution in the rainy season of Japan - A case study of 1997 July event, J. Aerosol Res., 20, 313322, doi:10.11203/jar.20.313, 2005 (in Japanese).

King, M. D., Kaufman, Y. J., Menzel, W. P., and Tanré, D.: Remote sensing of cloud, aerosol, and water vapor properties from the Moderate Resolution Imaging Spectrometer (MODIS), IEEE T. Geosci. Remote, 30, 2-27, doi:10.1109/36.124212, 1992.

Kokhanovsky, A. A., Davis, A. B., Cairns, B., Dubovik, O., Hasekamp, O. P., Sano, I., Mukai, S., Rozanov, V. V., Litvinov, P., Lapyonok, T., Kolomiets, I. S., Oberemok, Y. A., Savenkov, S., Martin, W., Wasilewski, A., Di Noia, A., Stap, F. A., Rietjens, J., Xu, F., Natraj, V., Duan, M., Cheng, T., and Munro, R.: Space-based remote sensing of atmospheric aerosols: The multiangle spectro-polarimetric frontier, Earth-Sci. Rev., 145, 85-116, doi:10.1016/j.earscirev.2015.01.012, 2015.

Martin, R. V., Jacob, D. J., Yantosca, R. M., Chin, M., and Ginoux, P.: Global and regional decreases in tropospheric oxidants from photochemical effects of aerosols, J. Geophys. Res., 108, 4097, doi:10.1029/2002JD002622, 2003.

Matsumoto, J.: Measurements of total radical reactivity of volatile organic compounds (VOCs) and total organic nitrates to evaluate secondary organic aerosol (SOA) formation, Earozoru Kenkyu, 29, 47-54, doi:10.11203/jar.29.s47, 2014 (in Japanese).

Omar, A. H., Won, J.-G., Winker, D. M., Yoon, S.-C., Dubovik, O., and McCormick, M. P.: Development of global aerosol models using cluster analysis of Aerosol Robotic Network (AERONET) measurements, J. Geophys. Res., 110, D10S14, doi:10.1029/2004JD004874, 2005.

Sano, I., Mukai, S., Okada, Y., Holben, B. N., Ohta, S., and Takamura, T.: Optical properties of aerosols during APEX and ACE-Asia experiments, J. Geophys. Res., 108, 8649, doi:10.1029/2002JD003263, 2003.

Sano, I., Mukai, M., Okada, Y., Mukai, S., Sugimoto, N., Matsui, I., and Shimizu, A.: Improvement of $\mathrm{PM}_{2.5}$ analysis by using AOT and lidar data, Proc. SPIE 7152, Remote Sensing of the Atmosphere and Clouds II, 71520M, doi:10.1117/12.804903, 2008.

Sano, I., Mukai, S., Holben, B. N., Nakata, M., Yonemitsu, M., Sugimoto, N., Fujito, T., Hiraki, T., Iguchi, N., Kozai, K., Kuji, M., Muramatsu, K., Okada, Y., Okada, Y., Sadanaga, Y., Tohno, S., Toyazaki, Y., and Yamamoto, K.: DRAGON-West Japan campaign in 2012: Regional aerosol measurements over Osaka, Proc. SPIE 8523, Remote Sensing of the Atmosphere, Clouds, and Precipitation IV, 85231M, doi:10.1117/12.977615, 2012.
Shimizu, A., Sugimoto, N., Matsui, I., Arao, K., Uno, I., Murayama, T., Kagawa, N., Aoki, K., Uchiyama, A., and Yamazaki, A.: Continuous observations of Asian dust and other aerosols by polarization lidars in China and Japan during ACE-Asia, J. Geophys. Res., 109, D19S17, doi:10.1029/2002JD003253, 2004.

Shimizu, A., Sugimoto, N., Matsui, I., and Nishizawa, T.: Direct comparison of extinction coefficients derived from Miescattering lidar and number concentrations of particles, subjective weather report in Japan, J. Quant. Spectrosc. Ra., 153, 7787, doi:10.1016/j.jqsrt.2014.12.005, 2015.

Shinozuka, Y. and Redemann, J.: Horizontal variability of aerosol optical depth observed during the ARCTAS airborne experiment, Atmos. Chem. Phys., 11, 8489-8495, doi:10.5194/acp-11-84892011, 2011.

Smirnov, A., Holben, B. N., Eck, T. F., Dubovik, O., and Slutsker, I.: Cloud-screening and quality control algorithms for the AERONET database, Remote Sens. Environ., 73, 337349, doi:10.1016/S0034-4257(00)00109-7, 2000.

Smirnov, A., Holben, B. N., Slutsker, I., Giles, D. M., McClain, C. R., Eck, T. F., Sakerin, S. M., Macke, A., Croot, P., Zibordi, G., Quinn, P. K., Sciare, J., Kinne, S., Harvey, M., Smyth, T. J., Piketh, S., Zielinski, T., Proshutinsky, A., Goes, J. I., Nelson, N. B., Larouche, P., Radionov, V. F., Goloub, P., Moorthy, K., Matarrese, R., Robertson, E. J., and Jourdin, F.: Maritime Aerosol Network as a component of Aerosol Robotic Network, J. Geophys. Res., 114, D06204, doi:10.1029/2008JD011257, 2009.

Sugimoto, N., Uno, I., Nishikawa, M., Shimizu, A., Matsui, I., Dong, X., Chen, Y., and Quan, H.: Record heavy Asian dust in Beijing in 2002: Observations and model analysis of recent events, Geophys. Res. Lett., 30, 1640, doi:10.1029/2002GL016349, 2003.

Takemura, T., Nozawa, T., Emori, S., Nakajima, T. Y., and Nakajima, T.: Simulation of climate response to aerosol direct and indirect effects with aerosol transport-radiation model, J. Geophys. Res., 110, D02202, doi:10.1029/2004JD005029, 2005.

van Donkelaar, A., Martin, R. V., Brauer, M., and Boys, B. L.: Use of satellite observations for long-term exposure assessment of global concentrations of fine particulate matter, Environ. Health Persp., 123, 135-143, doi:10.1289/ehp.1408646, 2015.

Villeneuve, P. J., Weichenthal, S. A., Crouse, D., Miller, A. B., To, T., Martin, R. V., van Donkelaar, A., Wall, C., and Burnett, R. T. Long-term exposure to fine particulate matter air pollution and mortality among Canadian women, Epidemiology, 26, 4, 536545, doi:10.1097/EDE.0000000000000294, 2015. 